\title{
Treatment strategies for oesophageal cancer - time-trends and long term outcome data from a large tertiary referral centre
}

\author{
Maria C Wolf ${ }^{*}$, Franz Zehentmayr ${ }^{1}$, Michael Schmidt ${ }^{2}$, Dieter Hölzel ${ }^{2}$ and Claus Belka ${ }^{1}$
}

\begin{abstract}
Background and objectives: Treatment options for oesophageal cancer have changed considerably over the last decades with the introduction of multimodal treatment concepts dominating the progress in the field. However, it remains unclear in how far the documented scientific progress influenced and changed the daily routine practice. Since most patients with oesophageal cancer generally suffer from reduced overall health conditions it is uncertain how high the proportion of aggressive treatments is and whether outcomes are improved substantially. In order to gain insight into this we performed a retrospective analysis of patients treated at a larger tertiary referral centre over time course of 25 years.
\end{abstract}

Patients and methods: Data of all patients diagnosed with squamous cell carcinoma (SCC) and adenocarcinoma (AC) of the oesophagus, treated between 1983 and 2007 in the department of radiation oncology of the LMU, were obtained. The primary endpoint of the data collection was overall survival (calculated from the date of diagnosis until death or last follow up). Changes in basic clinical characteristics, treatment approach and the effect on survival were analysed after dividing the cohort into five subsequent time periods (I-V) with 5 years each. In a second analysis any pattern of change regarding the use of radio(chemo)therapy $(R(C) T)$ with and without surgery was determined.

Results: In total, 503 patients with SCC (78.5\%) and AC (18.9\%) of the oesophagus were identified. The average age was 60 years (range $35-91$ years). 56.5\% of the patients were diagnose with advanced UICC stages III-IV. R(C)T was applied to $353(70.2 \%)$ patients; $\mathrm{R}(\mathrm{C}) \mathrm{T}+$ surgery was performed in $134(26.6 \%)$ patients, 63.8\% of all received chemotherapy (platinum-based 5.8\%, 5-fluorouracil (5-FU)12.1\%, 42.3\% 5-FU and mitomycin C (MMC)). The median follow-up period was 4.3 years. The median overall survival was 21.4 months. Over the time, patients were older, the formal tumour stage was more advanced, the incidence of AC was higher and the intensified treatment had a higher prevalence. However there was only a trend for an improved OS over the years with no difference between RCT with or without surgery $(p=0.09)$. The use of radiation doses over $54 \mathrm{~Gy}$ and the addition of chemotherapy $(p=0.002)$ were associated with improved OS.

Conclusion: Although more complex treatment protocols were introduced into clinical routine, only a minor progress in OS rates was detectable. Main predictors of outcome in this cohort was the addition of chemotherapy. The addition of surgery to radio-chemotherapy may only be of value for very limited patient groups.

Keywords: Oesophageal cancer, Radio-chemotherapy, Adenocarcinoma, Squamous cell carcinoma

\footnotetext{
* Correspondence: maria.wolf@med.uni-muenchen.de

'Department of Radiation Oncology, LMU University Hospital Munich,

Marchioninistraße 15, 81377 München, Germany

Full list of author information is available at the end of the article
} 


\section{Introduction}

Oesophageal cancer is generally associated with poor outcomes. However, over the last decades the treatment algorithms have changed considerably shifting from single mode treatments to complex multimodal approaches $[1,2]$.

Surgery is considered to be the mainstay of treatment especially in earlier stages, however a clear superiority over definitive radio-chemotherapy has not been proven so far [3]. In contrast, for locally advanced stages 5fluorouracil (5-FU)/cisplatin based radio-chemotherapy (RCT) regimens are the standard of care either in neoadjuvant or definitive concepts [4-11].

Although several trials and subsequent meta-analysis revealed a benefit for more aggressive approaches - at least in some sub-groups - the benefit in daily routine settings remains poorly defined. Since patients with oesophageal cancer frequently suffer from various comorbidities increasing the aggressiveness of any treatment may only be of value for a very limited subgroup of those patients $[6,7,11,12]$.

The introduction of radio-chemotherapy protocols, regardless of the use of platinum, offer a clear advantage when compared to radiotherapy alone $[7,13,14]$.

The analysis of triple modality approaches leads to a more complex picture: The French FFCD 9102 trial compared radio-chemotherapy plus surgery to radiochemotherapy alone. Local control and overall survival were almost identical at 2-years with a perioperative mortality of approximately $10 \%$ [4]. The authors conclude that there are no clear-cut benefits from the addition of surgery. Data from a similar German trial support these interpretations [9].

Nevertheless, the best outcomes were obtained in those patients with good response after neo-adjuvant RCT and complete resection during subsequent surgery. However, the benefits of improved local control are - at least partially - outweighed by increased surgical morbidity.

A meta-analysis resulted in improved survival rates when the outcomes of RCT followed by surgery were compared with surgery alone $[12,15]$. However this analysis did not really address the question in how far surgery is needed after good responses to RCT.

The value of most clinical trials on oesophageal cancer is limited to some degree because the clinical status of many of the patients in the 'real-live' setting prohibits the use of aggressive multi-modal protocols and thus the results of the respective trial may not be transferable to most patients.

In order to re-assess the value of different treatment approaches in oesophageal cancer in real life settings we analysed patient characteristics, stages distributions, treatment approaches and outcomes in a cohort of patients treated in one tertiary referral-centre over the last 25 years.

\section{Materials and methods \\ Patients}

In a retrospective approach, the following data were systematically retrieved from the original patient files: tumour stage (TNM/UICC version 6), treatment and outcome of all patients with either squamous cell carcinoma (SCC) or adenocarcinoma (AC) of the thoracic oesophagus, excluding AC from cardia and gastric involvement (GEJII+III). All retrospectively collected patient data were compared and crosschecked to data documented prospectively by the population-based Munich Cancer Registry (MCR, documentation started in 1978) for accuracy and completeness to prove the reliability and validity of our data.

Patients were treated between 1983 and 2007 at the department of radiation oncology at the hospital of the Ludwig Maximilian University. For this analysis all patients that presented with oesophageal carcinoma in this department were included, regardless of the form of therapy they received. Overall survival was defined as the survival time from diagnosis to death. Calculations for statistical significance were done only for non-metastatic (M0) patients. A previous published study analysed a subgroup of this collective in order to determine if a definitive RCT with $5 \mathrm{FU}$ and mitomycin $\mathrm{C}$ is as effective as the standard protocol with $5 \mathrm{FU} /$ cisplatin [13].

\section{Statistics}

Patient characteristics were compared by the Chi-square test. Survival data were analysed according to KaplanMeier (SPSS/WPSS ${ }^{\circledR}$ 18.0/19.0). Statistical significance was assessed by univariate and multivariate Cox proportional hazards regression model $(\mathrm{p}<0.05)$ and the log rank test. Patients who were coded as "alive" were censored at the time of last follow-up.

In order to visualize potential time trends, the whole cohort was arbitrarily divided into five treatment periods (five years duration): period $\mathrm{I}=1983-1987, \mathrm{II}=1988$ $1992, \mathrm{III}=1993-1997, \mathrm{IV}=1998-2002, \mathrm{~V}=2003-2007$.

\section{Results \\ Patients}

A total of 503 patients with cancer of the oesophagus were identified. The average number of patients treated per year was 20 (range 6-36). Table 1 shows the patient characteristics of the study population. The median age at diagnosis was 61 years (range 35 to 91 years), 10\% were younger than 47 years, $10 \%$ older than 77 years at diagnosis. 
Table 1 Patient characteristics and treatment options, all patients, 1983-2007

\begin{tabular}{|c|c|c|c|}
\hline Variable & Subgroup & $n=503$ & $\%$ \\
\hline \multirow[t]{2}{*}{ Gender } & $M$ & 400 & 79.5 \\
\hline & W & 103 & 20.5 \\
\hline \multirow[t]{6}{*}{ Age } & $<50$ & 73 & 14.5 \\
\hline & $50-59$ & 158 & 31.4 \\
\hline & $60-69$ & 151 & 30 \\
\hline & $70+$ & 121 & 24.1 \\
\hline & median y & 61 & \\
\hline & range y & $35-91$ & \\
\hline \multirow[t]{3}{*}{ Histology } & $A C$ & 95 & 18.9 \\
\hline & SCC & 395 & 78.5 \\
\hline & unknown & 13 & 2.6 \\
\hline \multirow[t]{3}{*}{ Grading } & $\mathrm{G} 1+2$ & 217 & 43.2 \\
\hline & $\mathrm{G} 3+4$ & 262 & 52.1 \\
\hline & unknown & 14 & 2.8 \\
\hline \multirow[t]{4}{*}{$\mathrm{T}$} & $\mathrm{T} 1+2$ & 114 & 22.7 \\
\hline & T3 & 259 & 51.5 \\
\hline & $\mathrm{T} 4$ & 90 & 17.9 \\
\hline & unknown & 39 & 7.8 \\
\hline \multirow[t]{3}{*}{$\mathrm{N}$} & No & 203 & 40.4 \\
\hline & N1 & 253 & 50.3 \\
\hline & unknown & 47 & 9.3 \\
\hline \multirow[t]{2}{*}{ M } & M1 & 113 & 22.5 \\
\hline & unknown & 28 & 5.6 \\
\hline \multirow[t]{3}{*}{ UICC } & $|-| \mid B$ & 190 & 37.8 \\
\hline & III+IV & 281 & 55.9 \\
\hline & unknown & 32 & 6.4 \\
\hline \multirow[t]{5}{*}{ Localisation } & cervical & 23 & 4.6 \\
\hline & upper thoracic & 114 & 22.7 \\
\hline & mid thoracic & 147 & 29.2 \\
\hline & lower thoracic & 201 & 40 \\
\hline & unknown & 18 & 3.6 \\
\hline \multirow[t]{16}{*}{ Therapy } & prim. & 353 & 70.2 \\
\hline & $\mathrm{RT} / \mathrm{RCT}$ & $125 / 227$ & $(35.4 / 64.3)$ \\
\hline & adjuvant & 51 & 10.1 \\
\hline & $\mathrm{RT} / \mathrm{RCT}$ & $20 / 28$ & $(39.2 / 54.9)$ \\
\hline & neoadj. & 83 & 16.5 \\
\hline & $\mathrm{RT} / \mathrm{RCT}$ & $17 / 63$ & $(20.5 / 75.9)$ \\
\hline & unknown & 16 & 3.2 \\
\hline & RT & 172 & 34.2 \\
\hline & $\mathrm{RCT}$ & 322 & 64 \\
\hline & unknown & 9 & 1.8 \\
\hline & Chemotherapy & 322 & 100 \\
\hline & $5 F U+M M C$ & 213 & 66.1 \\
\hline & 5FU+Cisplatin & 22 & 6.8 \\
\hline & $5 F U$ & 61 & 18.9 \\
\hline & cisplatin & 8 & 2.5 \\
\hline & unknown & 18 & 5.6 \\
\hline \multirow[t]{3}{*}{ RT dose in Gy } & $\leq 50$ & 151 & 30 \\
\hline & $>50-\leq 54$ & 72 & 14.3 \\
\hline & $\geq 54-<60$ & 85 & 16.9 \\
\hline
\end{tabular}

Table 1 Patient characteristics and treatment options, all patients, 1983-2007 (Continued)

\begin{tabular}{llll}
\hline & $\geq 60$ & 168 & 33.7 \\
& unknown & 17 & 3.4 \\
2D/3Dplanning & $2 \mathrm{D}$ & 289 & 57.5 \\
& $3 \mathrm{D}$ & 180 & 35.8 \\
AL only & & 7 & 1.4 \\
\hline
\end{tabular}

Patients with AC were significantly older with a median age of 65 compared to SCC with a median age of 60 years at diagnosis. 20.8\% SCC and 38.9\% AC were older than 70 years at diagnosis $(\mathrm{p}<.0001)$, they also present a worse grading $(\mathrm{p}=0.02)$ and unfavourable staging with more metastatic disease $(\mathrm{p}=0.04)$. Histology distribution was independent of gender (Table 2).

At diagnosis 311 of all patients $(62.5 \%)$ were classified as $\geq$ UICC stage IIB, $113(22.5 \%)$ already presented with metastatic disease, $60(11,9 \%)$ were diagnosed with other malignancies such as tumours of the oral cavity, SCLC, bladder cancer etc.

The predominant tumour sites were the mid- and the lower thoracic third with 147 (29.2\%) and 201 (40\%).

SCC was found in all subsections (26\% cervical, 33\% mid-oesophagus, $35 \%$ distal). AC predominantly in the distal third (65\%) of the oesophagus (Table 1).

\section{Treatment strategy}

$353(70.2 \%)$ patients were considered to be inoperable because of poor KPS, co-morbidities, locally non-resectable or metastatic disease. $172(34.2 \%)$ received radiotherapy only (RT), 322 (64\%) radio-chemotherapy (RCT). Treatment groups were divided in two major categories: RT or RCT as definitive treatment $(\mathrm{n}=353,70.2 \%)$ and $\mathrm{RT} / \mathrm{RCT}$ combined with surgery $(\mathrm{n}=134,26.6 \%)$. In the surgery group 51 patients (38\%) received adjuvant and 83 (61.9\%) neoadjuvant $\mathrm{R}(\mathrm{C}) \mathrm{T}$. A two-agent chemotherapy

Table 2 Distribution of adenocarcinoma (AC) and squamous cell carcinoma (SCC)

\begin{tabular}{llll}
\hline & $\mathbf{S C C}(\mathbf{n}=\mathbf{3 9 5})$ & $\mathbf{A C}(\mathbf{n}=\mathbf{9 5})$ & $\mathbf{p}$-value \\
\hline Male & $317(80.3)$ & $71(74.7)$ & 0.23 \\
Age & & & \\
$<60$ & $195(49.4)$ & $32(33.7)$ & 0.006 \\
$60-69$ & $118(29.9)$ & $26(27.4)$ & \\
$70-$ & $82(20.8)$ & $37(38.9)$ & $<0.0001$ \\
G3+4 & $192(48.6)$ & $61(64.2)$ & 0.02 \\
T1-2 & $94(25.5)$ & $17(20.5)$ & 0.33 \\
T3 & $201(50.9)$ & $51(53.7)$ & n.s. \\
T4 & $73(18.5)$ & $15(15.8)$ & n.s. \\
N+ & $198(50.1)$ & $48(50.5)$ & n.S. \\
M1 & $83(22.0)$ & $28(32.2)$ & 0.04 \\
\hline
\end{tabular}


(5-FU/MMC) was applied in 235 cases (73\%) and either $5 \mathrm{FU}$ or cis-platinum in $30.7 \%$. The radiation dose was below 50 Gy in 151 (30\%) patients, between 50 and 59 Gy in 157 (31.2\%) and in 168 (33.7\%) 60 Gy or more. Radiotherapy was applied by a $3 \mathrm{D}$ conformal CT-plan in $180(35.8 \%)$ patients since 1998 , a 2 D technique was used before 1998 in 289 (57.5\%) cases.

62 patients $(12.3 \%)$ died during or shortly after treatment i.e. intraoperative ( 3 patients), after surgery ( 23 patients $(17,2 \%)$ from 134 who received surgery), before, during or less than 4 weeks after $\mathrm{R}(\mathrm{C}) \mathrm{T}$ (53 patients $(15 \%)$ from 353). Considering M0 patients the rate declines to $9.8 \%$ for definitive $\mathrm{R}(\mathrm{C}) \mathrm{T}$ but remains the same for the surgery group. In $43(8.5 \%)$ patients treatment was stopped prematurely. The proportion of patients older than 65 who underwent surgery was half of number of patients below $65(\mathrm{p}<.0001) .70 \%$ of the patients received chemotherapy in the definitive RT group whereas only $30 \%$ in the surgery group (Table 1 ).

\section{Time trends}

Changes in patient characteristics, therapeutic strategies

The average age at diagnosis increased from $59 \mathrm{y}$ to $65 \mathrm{y}$. The underlying histology shifted from SCC to AC in our cohort with a significant rise in the prevalence of AC from $16.1 \%$ to $27.1 \%(\mathrm{p}=0.04)$. In parallel a shift toward more malignant and more advanced tumour stages was observed (grading $(\mathrm{p}=0.003), \mathrm{T}$-stage $(\mathrm{p}=$ $0.003)$, N-stage $(p<0.0001)$ and - consecutively - UICC stages III and IV ( $\mathrm{p}$.0001) (Table 2). The use of concomitant radio-chemotherapy protocols increased continuously over all time periods, from $37.8 \%$ in period I to a proportion of $86.1 \%$ in period V $(\mathrm{p}<.0001)$ with a two agent approach being used most frequently.

Definitive treatment setting increased from $65.7 \%$ in period I to $71 \%$ and $78.8 \%$ in period III and V respectively. The application of a definitive RCT increased extremely after 1993 with a significant difference comparing time before and after $1998(\mathrm{p}<.0001)$. A slight decrease in $\mathrm{R}$ (C) T combined with surgery can be observed (n.s.).

Higher radiation doses (54 to $60 \mathrm{~Gy}$ ) were applied significantly more often after 1998.

In order to further validate the results, our own data were compared with the complete data set documented in the MCR. In general, MCR covers the region of central Bavaria, however, these data do not contain detailed radiation data and are restricted to a key set of base line data including histology, stage, general treatment approach and outcome. Thus only parts of the results can be validated using the MRC data. Nevertheless, in the analysis of their own data the MRC reveals a similar gender-, age- and tumour stage- distribution over the time (Table 3).

The shift in treatment strategies in the catchment area of the MRC strongly resembles the in house situation:
Decreasing rates of surgery, radiotherapy only, decreasing rates of surgery and adjuvant radiotherapy only, increasing use of RCT and RCT+surgery.

\section{Overall survival and prognosis}

Figure 1 shows the OS curves for the five periods. In general, no statistically significant improvement in OS rate was seen over the time course (Figure 2). Even comparing period I and V, no significant outcome improvement was observed (Figure 3).

A significant improvement of the OS rates was found when outcomes after RCT were compared to those after RT only ( $p=0.002)$, regardless of the chemotherapy protocol used (2 substances vs. single-agent (n. s.)). In parallel, a radiation dose higher than 54 Gy seems to have an influence on survival $(p=0.027)$, decreasing at doses higher than 60 Gy $(\mathrm{p}=0.04)$ but only $\mathrm{RCT}$ remains significant in the multivariate Cox proportional hazard analysis (Table 4)

Yet it is highly noteworthy that the superiority in OS for patients in the surgery group seen before 1998 (period IIII) is no longer visible comparing $R(C) T$ versus $R(C) T$ +surgery for patients diagnosed between 1998 and 2007 (period IV+V) and the OS curves converge (Figures 4a, b). When patients received $\mathrm{R}(\mathrm{C}) \mathrm{T}$ an improvement (n.s.) in OS can be observed comparing the periods. There was no improvement when $\mathrm{R}(\mathrm{C}) \mathrm{T}$ +surgery was performed.

\section{Discussion}

Primary aim of this study was to assess changes in basic clinical characteristics, treatment approaches and their impact on survival in a very large cohort of patients followed over a long period of time. Secondly, we analysed patterns of change in the use of radio-(chemo)therapy with or without surgery. For comparison with epidemiological data we included M1 patients but removed them for not compromising the informative value.

In general, there was a clear shift over the observation period regarding fundamental patient characteristics towards higher ages, a higher proportion of adenocarcinoma and towards more advanced tumour stages at diagnosis. Similar tendencies were also visible when analysing the complete epidemiologic data of the Munich Cancer Registry. Stage shift and stage migration is - at least in part - related to an increasing utilisation of improved staging possibilities including Endo-US, MRI and PET-CT [16-20].

The increased rate of adenocarcinoma was already reported by multiple groups world-wide and potentially reflects a completely different pathogenesis [21-27].

However, the shift towards adenocarcinoma is slightly less pronounced when compared to the SEER database (59.2\%, $\mathrm{n}=16,162 ; 2004-2008)$. As opposed to literature $[4,28]$ we detected a worse OS for AC patients than in 
Table 3 Timetrends, all patients distributed in the five equal time periods (5 y each) and compared to available MCR data

\begin{tabular}{|c|c|c|c|c|c|c|}
\hline \multicolumn{2}{|l|}{ Time period } & $\begin{array}{l}\text { I: } 1983-1987 \\
n=143(\%)\end{array}$ & $\begin{array}{l}\text { II: } 1988-1992 \\
n=98(\%)\end{array}$ & $\begin{array}{l}\text { III: 1993-1997 } \\
n=69(\%)\end{array}$ & $\begin{array}{l}\text { IV: } 1998-2002 \\
n=108(\%)\end{array}$ & $\begin{array}{l}\text { V: } 2003-2007 \\
n=85(\%)\end{array}$ \\
\hline \multirow[t]{2}{*}{ Gender } & M & 115(80.4) & $76(77.6)$ & $52(75.4)$ & $92(85.2)$ & $65(76.5)$ \\
\hline & MCR & $(84.0)$ & $(83.2)$ & $(83.0)$ & $(79.0)$ & $(80.4)$ \\
\hline \multirow[t]{2}{*}{ Age } & median y & 59 & 60 & 59 & 60 & 65 \\
\hline & MCR & 58 & 59 & 61 & 65 & 66 \\
\hline \multirow[t]{2}{*}{ Histology } & $\mathrm{AC} / \mathrm{SCC}$ & $23(16.1) / 117(81.8)$ & $14(14.3) / 81(82.7)$ & $12(17.4) / 56(81.2)$ & $23(21.3) / 81(75)$ & $23(27.1) / 60(70.6)$ \\
\hline & MCR & $(16.5) /(83.5)$ & $(22.9) /(77.1)$ & $(27.6) /(72.4)$ & & \\
\hline Grading & $\mathrm{G} 3+4$ & $61(42.7)$ & $48(49)$ & $40(58)$ & $64(59.3)$ & $49(57.6)$ \\
\hline $\mathrm{T}$ & $\mathrm{T} 3+4$ & $76(53.2)$ & $61(62.2)$ & $55(79.7)$ & $90(83.4)$ & $65(76.6)$ \\
\hline N1 & & $53(37.1)$ & $36(36.7)$ & $40(58)$ & $65(60.2)$ & $59(69.4)$ \\
\hline M1 & & $27(20.9)$ & $17(19.1)$ & $15(22.1)$ & $29(27.6)$ & $25(29.8)$ \\
\hline \multirow[t]{5}{*}{ UICC } & $|-| \mid B$ & $68(47.6)$ & $45(45.9)$ & 24(34.8) & $32(29.6)$ & $21(24.7)$ \\
\hline & $M C R$ & $(34.4)$ & 1988-2007 (37.0) & & & \\
\hline & III-IV & $61(42.7)$ & $43(43.9)$ & $43(62.3)$ & $74(68.5)$ & $63(74.1)$ \\
\hline & MCR & $(51.1)$ & 1988-2007 (63.1) & & & \\
\hline & unknown & $14(9.8)$ & $10(10.2)$ & $2(2.9)$ & $2(1.9)$ & $1(1.2)$ \\
\hline \multirow[t]{6}{*}{ Therapy } & definitive & $94(65.7)$ & $66(67.3)$ & $49(71)$ & $77(71.3)$ & $67(78.8)$ \\
\hline & $\mathrm{RT} / \mathrm{RCT}$ & $55(58.5) / 38(40.4)$ & $37(56.1) / 29(43.9)$ & $13(26.5) / 36(73.5)$ & 10(13)/67(87) & $11(16.4) / 56(83.6)$ \\
\hline & adjuvant & $21(14.7)$ & $4(4.1)$ & $9(13.0)$ & $10(9.3)$ & $7(8.2)$ \\
\hline & $\mathrm{RT} / \mathrm{RCT}$ & 14(66.7)/4(19) & $1(25) / 3(75)$ & $3(33.3) / 6(66.7)$ & $2(20) / 8(80)$ & 0/7(100) \\
\hline & neoadjuvant & $20(14.0)$ & $24(24.5)$ & $10(14.5)$ & $19(17.6)$ & 10(11.8) \\
\hline & $\mathrm{RT} / \mathrm{RCT}$ & 7(35)/12(60) & $4(16.7) / 19(79.2)$ & $2(20) / 8(80)$ & $3(15.8) / 16(84.2)$ & $1(10) / 8(80)$ \\
\hline RT, M0-patients & & $56(56.6)$ & $26(36.1)$ & $13(24.5)$ & $9(11.8)$ & $6(10.3)$ \\
\hline RCT, M0-patients & & $43(43.4)$ & $46(63.9)$ & $40(75.5)$ & $67(88.2)$ & $52(89.7)$ \\
\hline Surgery, M0-patients & & $33(32.7)$ & $22(30.6)$ & $16(30.2)$ & 25(33.8) & $16(27.1)$ \\
\hline \multirow[t]{3}{*}{ RT dose in Gy, M0-pat. } & $\leq 54$ & $45(47.4)$ & $36(50)$ & $23(43.4)$ & $38(51.4)$ & 20(33.9) \\
\hline & $>54-<60$ & $4(4.2)$ & 0 & $6(11.3)$ & $17(23)$ & $27(45.8)$ \\
\hline & $60+$ & $46(48.4)$ & $36(50)$ & $24(45.3)$ & $19(25.7)$ & $12(20.3)$ \\
\hline 2D/3D-planning & & 142(99.3)/0 & $98(100) / 0$ & $65(94.2) / 1(1.4)$ & $7(6.5) / 99(91.7)$ & $2(2.4) / 82(96.5)$ \\
\hline Peri-therapy death & & 19(13.3) & $11(11.2)$ & $9(13.0)$ & 15(13.9) & $8(9.5)$ \\
\hline \multicolumn{2}{|c|}{ Therapy break up due to complications } & $13(9.1)$ & $4(4.1)$ & $7(10.1)$ & 13(12.0) & $6(7.1)$ \\
\hline \multirow[t]{4}{*}{ Overall survival all/MO } & median & $18.9 / 20.7$ & 20.6/26.1 & $22.6 / 27.3$ & $20.7 / 24.3$ & 20.3/29.7 \\
\hline & $1 y$ & $(41.1) /(43.7)$ & $(40.2) /(52.2)$ & $(44.9) /(54.7)$ & $(40.7) /(44.7)$ & $(48.8) /(58.7)$ \\
\hline & $3 y$ & $(7.1) /(8.7)$ & $(15.1) /(18.3)$ & $(14.5) /(18.9)$ & $(17.6) /(19.7)$ & $(15.9) /(19.4)$ \\
\hline & $5 y$ & $(4.0) /(5.5)$ & $(8.6) /(8.2)$ & $(10.1) /(13.2)$ & $(9.3) /(11.8)$ & $(9.8) /(15.1)$ \\
\hline
\end{tabular}

patients with SCC, possibly because of the negative patient selection in our cohort. The proportion of synchronous malignancies of $11.9 \%$ in our cohort is well in line with published data $[29,30]$.

In general, the prognosis of oesophageal cancer is dominated by two competing risks: loco-regional relapse and distant metastases. Surgery as well as radiation as single modality approaches yield 5 y survival rates below $10 \%$ [31]. With both approaches local control rates are far from being optimal. For this reason surgery, radiotherapy and chemotherapy were combined in a multimodality approach. As expected, in our cohort therapy options shifted towards multimodality. However, only the combination of radiotherapy with chemotherapy seems to impact on overall survival. This has already been shown in the framework of prospective randomized trials $[8,32,33]$ and also for patients treated along the given trial protocols but formally outside of the randomized trial [7]. However, no such data have been shown for a non-selected patient cohort. Of special notice in this regard is the fact that most patients in the Munich setting have received mitomycin- $C$ [13] instead of cisplatin which was used in most of the randomized trials $[7,8,14,33]$. Interestingly, the addition of chemotherapy only increases local control and was never found to reduce the high rate of loco-regional and distant seeding.

However, for the whole study cohort the improvements in the field of radio-chemotherapy were not 


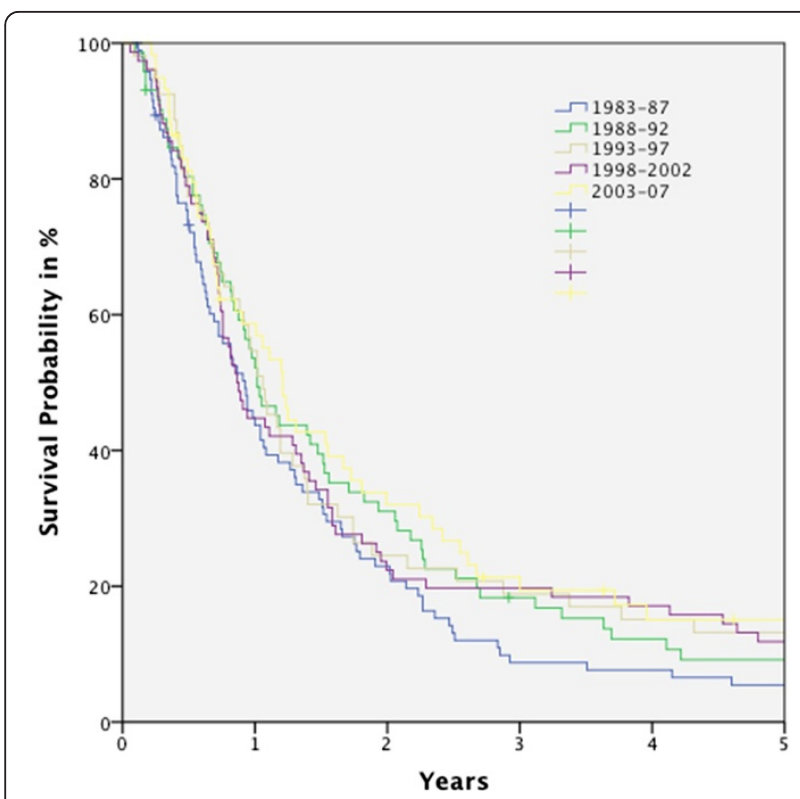

Figure 1 Kaplan-Meier curve for overall survival (OS) for all Mo-patients $(n=362)$ distributed to the five time-periods.

prominent enough to significantly increase OS rates. Thus, despite considerable changes in the treatment regimens over the past decades results are still moderate and only a slight improvement in OS was seen in this unselected patient-cohort.

When trying to determine the role of surgery using our patient cohort some limitations have to be

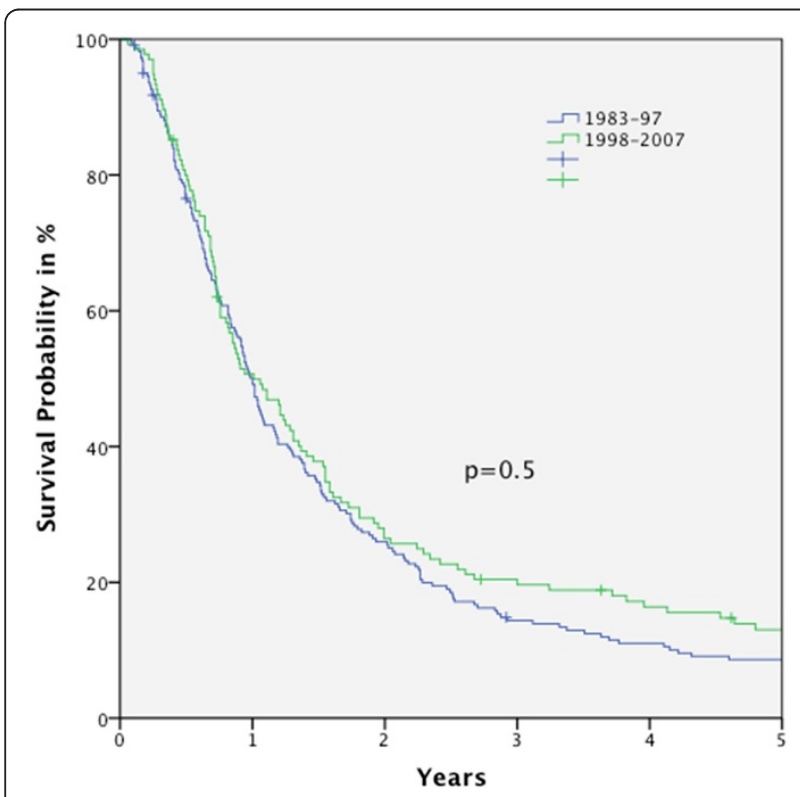

Figure 2 Kaplan-Meier curve for overall survival (OS) for all M0-patients ( $n=362)$, comparison between OS for patients diagnosed between 1983 and 1997 and between 1998 and 2007

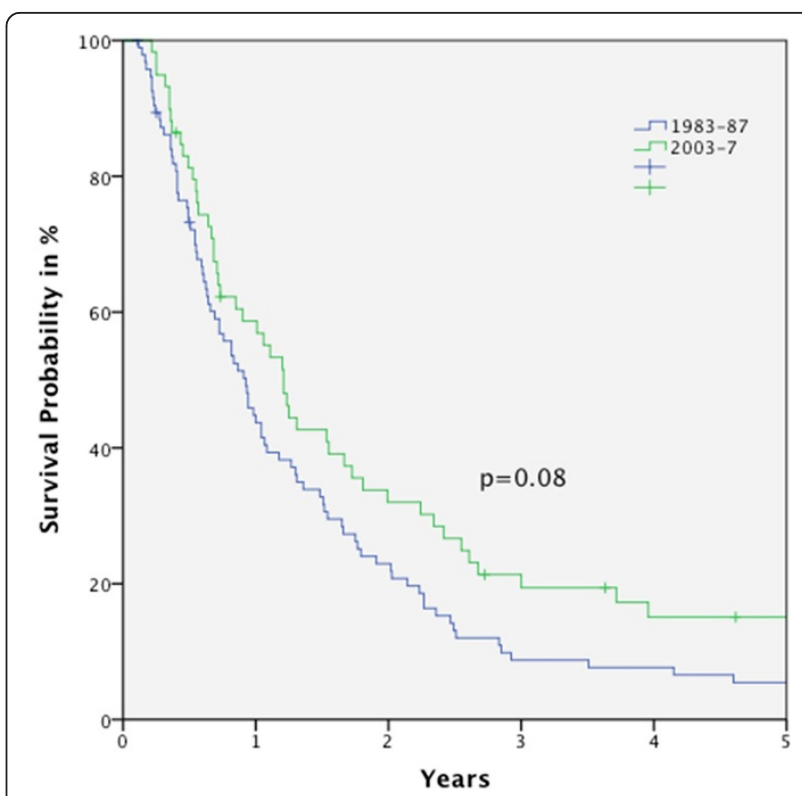

Figure 3 Kaplan-Meier curve for OS for patients diagnosed in period I (1983-1987) compared to period V (2003-2007), improvement in OS is not significant $(p=0.08)$.

considered: The most striking bias is the fact that all patients have been selected to receive radiotherapy based on clinical reasons. Thus, the value of surgery can only be estimated for those patients. In our cohort, the value of surgery for overall survival seems to be limited. This is in accordance with the results of randomized trial showing that the addition of surgery to combined radio-chemotherapy does not increase OS $[3,4,9]$. Despite the fact that the best results regarding survival are achieved in patients with triple modality approaches the impact on a larger cohort is limited. This is related to the fact that the increase in mortality by the addition of surgery counteracts the effects of an increased local control. Thus, no clear contribution of surgery to the outcome is visible in our cohort.

Importantly, radiation dose was related to OS-rates in this large cohort. In a previous randomized trial [34] no such correlation was documented. However the value of this trial is strongly limited since most of the excess mortality in the higher dose arm occurred early in the treatment course and several protocol violations were documented. Our findings are in accordance with data published by Geh [35] who has provided evidence for clear dose response relationships for oesophageal cancer based on dose response data compiled from multiple trials.

As already pointed out, the use of a non-selected patient cohort for study purposes is associated with certain shortcomings: It is impossible to control for imbalances due to individual and location specific clinical 
Table 4 Cox Regression Analysis, HR = Hazard Ratio calculated with 95\% confidence interval (CI) by Cox-proportional hazard model

\begin{tabular}{llll}
\hline & & Overall survival \\
& Univariate $\mathbf{p}, \mathbf{H R}(\mathbf{9 5} \% \mathbf{C l})$ & Multivariate $\mathbf{p}, \mathbf{H R}(\mathbf{9 5} \% \mathbf{C l})$ \\
\hline Therapy & Comparison & & \\
& prim vs adj+neoadj RCT & $0.096,1.23(0.97-1.56)$ & $0.02,0.74(0.58-0.98)$ \\
& RCT vs RT & $\mathbf{0 . 0 0 2}, 0.69(0.54-0.87)$ & \\
RT dose in Gy & 1 agent vs 2 agents & $0.34,1,04(0.97-1.11)$ & $0.18,0.85(0.67-1.089$ \\
2D/3Dplanning & $\geq 54$ Gy vs $<54$ Gy & $\mathbf{0 . 0 2 7}, 0.78(0.62-0.97)$ & \\
\hline
\end{tabular}

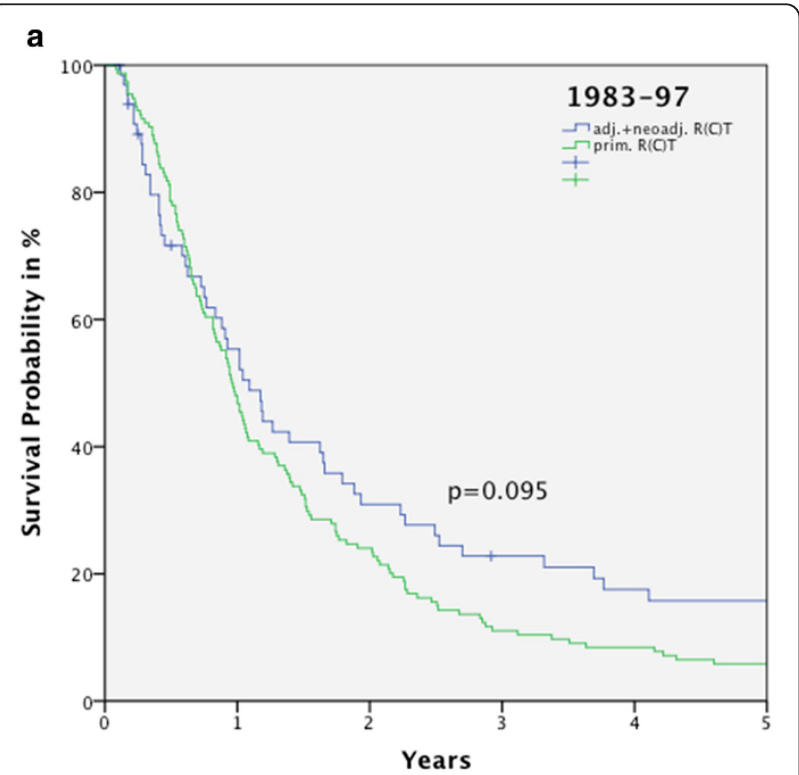

b

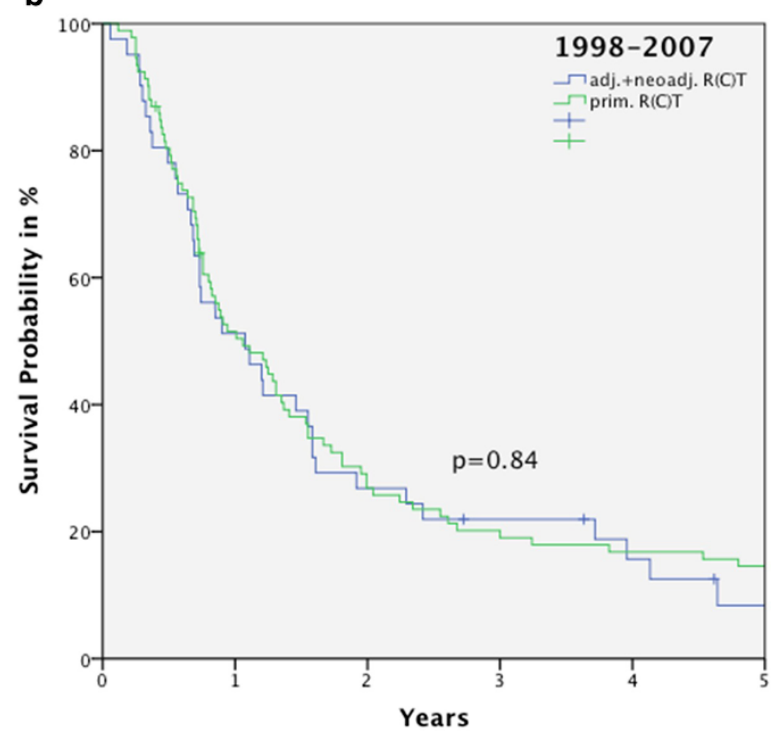

Figures 4 Kaplan-Meier curves for OS for patients diagnosed between 1983 and 1997 who received $R(C) T$ compared to $R(C)$ $\mathrm{T}+$ surgery presenting a better outcome $(4 \mathrm{a})$ and presenting no difference in OS in the two therapy groups between 1998 and 2007 (4b). decisions. In addition, time trends are influenced by general scientific progress but also by centre specific variables. Thus, all interpretations need to be very careful, considering selection bias in this retrospective setting for such a long period of time. The patient characteristics in our unselected cohort are comparable with whole epidemiologic data set of the Munich Cancer Registry (MCR) and published trials. Thus the resulting conclusions are substantiated to some degree. Up to now only very few other trials have tried to approach the value of treatment approaches in oesophageal cancer using population-based data. In this regard a US group supported by the National Institutes of Health used the instrument of a survey to collect demographic data on patient and information on surgical approach for oesophageal carcinoma across the whole country [36]. The evaluation showed that there is a substantial heterogeneity in surgery strategies and emphasized the need of controlled trials to determine best practices. Another study from the US queried the SEER database to prove the benefit of neoadjuvant RT on survival for patients undergoing definitive surgery [37]. Also by SEER-query Chang et al. [28] found no difference in survival and response between AC and SCC across any of the major treatment modalities.

An investigation on trends in treatment and factors influencing treatment receipt and survival were sourced from the Irish National Cancer Registry [38] and showed decreased use of surgery, especially in older patients and a considerable difference between the survival observed at population level and in randomised controlled trials.

The MCR and the SEER registry are population-based databases that represent an unselected group of patients without consistently recorded medical or course information. Therefore only statements concerning epidemiology and outcomes in actual clinical practice outside of the controlled setting of research protocols can be obtained. Although course and recurrence information is poor in our data and also in the databases, overall survival is a good surrogate for disease recurrence, because the outcomes with oesophageal cancer are poor 
and recurrences in this disease are rarely salvaged. Cause of death and mortality data are available and generally corresponds to disease recurrence.

Despite the fact that the results of several large randomized trials are available the general progress in oesophageal cancer is limited. In the future, several crucial aspects are of importance: A key problem is the fact that a considerable number of patients are not suitable for aggressive approaches [39]. Hence, major efforts should be placed on the development of tools for accurate patient selection according to the individual risk situation and estimated prognosis and reducing therapy associated morbidity and mortality $[22,25,31,40,41]$. In this regard, important contributions may come from similar disorders including head and neck cancer or lung cancer in which the development of modern imaging approaches as well as biological stratification approaches already dominate the research horizon $[42,43]$.

In parallel, the fate of patients with oesophageal cancer is largely influenced by early dissemination, thus it is of key importance to test the value of an integration of targeted drugs with proven activity in either SCC or AC into putative new treatment protocols [44-46]. Similarly, new radiation techniques suitable to reduce lung toxicity or increase target volume conformity [47-50] will have a clear role in optimizing the outcomes in oesophageal cancer.

\section{Conclusion}

Despite an increase in unfavourable tumour stages a slight (but statistically insignificant) improvement of survival for the whole cohort can be observed, which can be mainly attributed to the addition of chemotherapy to radiotherapy. The role of surgery for most of the patients with locally advanced disease is not fully determined. Despite all efforts in the field of multimodal approaches, prognosis of oesophageal cancer is still limited.

\footnotetext{
Author details

'Department of Radiation Oncology, LMU University Hospital Munich, Marchioninistraße 15, 81377 München, Germany. ${ }^{2}$ Institute for medical Information processing, Biometry and Epidemiology, LMU University Hospital Munich, Marchioninistraße 15, 81377 München, Germany.
}

\section{Authors' contributions}

MCW carried out the retrospective data acquisition, performed the statistical analysis and drafted the manuscript, FZ participated in data analysis, manuscript preparation and revision, MS and DH participated in data acquisition, the statistical analysis and interpretation of data, CB provided the idea, contributed to the conception of the trial, drafting and revision of the manuscript. All authors read and approved the final manuscript.

\section{Competing interests}

The authors declare that they have no competing interests.
Received: 15 November 2011 Accepted: 15 April 2012

Published: 15 April 2012

\section{References}

1. Berger B, Belka C: Evidence-based radiation oncology: oesophagus. Radiother Oncol 2009, 92(2):276-290

2. Wolf MC, Stahl M, Krause BJ, Bonavina L, Bruns C, Belka C, Zehentmayr F: Curative treatment of oesophageal carcinoma: current options and future developments. Radiat Oncol 2011, 6:55.

3. Chiu PW, Chan AC, Leung SF, Leong HT, Kwong KH, Li MK, Au-Yeung AC, Chung SC, Ng EK: Multicenter prospective randomized trial comparing standard esophagectomy with chemoradiotherapy for treatment of squamous esophageal cancer: early results from the Chinese University Research Group for Esophageal Cancer (CURE). J Gastrointest Surg 2005, 9(6):794-802.

4. Bedenne L, Michel P, Bouche O, Milan C, Mariette C, Conroy T, Pezet D, Roullet B, Seitz JF, Herr JP, et al: Chemoradiation followed by surgery compared with chemoradiation alone in squamous cancer of the esophagus: FFCD 9102. J Clin Oncol 2007, 25(10):1160-1168.

5. Bosset JF, Gignoux M, Triboulet JP, Tiret E, Mantion G, Elias D, Lozach P, Ollier JC, Pavy JJ, Mercier M, et al: Chemoradiotherapy followed by surgery compared with surgery alone in squamous-cell cancer of the esophagus. N Engl J Med 1997, 337(3):161-167.

6. Burmeister BH, Smithers BM, Gebski V, Fitzgerald L, Simes RJ, Devitt $P$, Ackland S, Gotley DC, Joseph D, Millar J, et al: Surgery alone versus chemoradiotherapy followed by surgery for resectable cancer of the oesophagus: a randomised controlled phase III trial. Lancet Oncol 2005, 6(9):659-668.

7. Cooper JS, Guo MD, Herskovic A, Macdonald JS, Martenson JA Jr, AlSarraf M, Byhardt R, Russell AH, Beitler JJ, Spencer S, et al: Chemoradiotherapy of locally advanced esophageal cancer: long-term follow-up of a prospective randomized trial (RTOG 85-01). Radiation Therapy Oncology Group. Jama 1999, 281(17):1623-1627.

8. Herskovic A, Martz K, al-Sarraf M, Leichman L, Brindle J, Vaitkevicius V, Cooper J, Byhardt R, Davis L, Emami B: Combined chemotherapy and radiotherapy compared with radiotherapy alone in patients with cancer of the esophagus. N Engl J Med 1992, 326(24):1593-1598.

9. Stahl M, Stuschke M, Lehmann N, Meyer HJ, Walz MK, Seeber S, Klump B, Budach W, Teichmann R, Schmitt M, et al: Chemoradiation with and without surgery in patients with locally advanced squamous cell carcinoma of the esophagus. J Clin Oncol 2005, 23(10):2310-2317.

10. Stahl M, Walz MK, Stuschke M, Lehmann N, Meyer HJ, Riera-Knorrenschild J, Langer P, Engenhart-Cabillic R, Bitzer M, Konigsrainer A, et al: Phase III comparison of preoperative chemotherapy compared with chemoradiotherapy in patients with locally advanced adenocarcinoma of the esophagogastric junction. J Clin Oncol 2009, 27(6):851-856.

11. Walsh TN, Noonan N, Hollywood D, Kelly A, Keeling N, Hennessy TP: A comparison of multimodal therapy and surgery for esophageal adenocarcinoma. N Engl J Med 1996, 335(7):462-467.

12. Gebski V, Burmeister B, Smithers BM, Foo K, Zalcberg J, Simes J: Survival benefits from neoadjuvant chemoradiotherapy or chemotherapy in oesophageal carcinoma: a meta-analysis. Lancet Oncol 2007, 8(3):226-234.

13. Wolf M, Zehentmayr F, Niyazi M, Ganswindt U, Haimerl W, Schmidt M, Holzel D, Belka C, et al: Long-term outcome of mitomycin C- and 5-FUbased primary radiochemotherapy for esophageal cancer. Strahlentherapie und Onkologie. Organ der Deutschen Rontgengesellschaft 2010, 186(7):374-381.

14. Wong R, Malthaner R: Combined chemotherapy and radiotherapy (without surgery) compared with radiotherapy alone in localized carcinoma of the esophagus. Cochrane Database Syst Rev 2006, , 1: CD002092.

15. Sjoquist KM, Burmeister BH, Smithers BM, Zalcberg JR, Simes RJ, Barbour A, Gebski V: Survival after neoadjuvant chemotherapy or chemoradiotherapy for resectable oesophageal carcinoma: an updated meta-analysis. The lancet oncology 2011, 12(7):681-692.

16. Polednak AP: Trends in survival for both histologic types of esophageal cancer in US surveillance, epidemiology and end results areas. International journal of cancer Journal international du cancer 2003, 105(1):98-100 
17. Allum WH, Griffin SM, Watson A, Colin-Jones D: Guidelines for the management of oesophageal and gastric cancer. Gut 2002, 50(Suppl 5): v1-23.

18. Fletcher JW, Djulbegovic B, Soares HP, Siegel BA, Lowe VJ, Lyman GH, Coleman RE, Wahl R, Paschold JC, Avril N, et al: Recommendations on the use of 18F-FDG PET in oncology. J Nucl Med 2008, 49(3):480-508.

19. van Vliet EP, Heijenbrok-Kal MH, Hunink MG, Kuipers EJ, Siersema PD: Staging investigations for oesophageal cancer: a meta-analysis. British journal of cancer 2008, 98(3):547-557.

20. Wallace MB, Nietert PJ, Earle C, Krasna MJ, Hawes RH, Hoffman BJ, Reed CE: An analysis of multiple staging management strategies for carcinoma of the esophagus: computed tomography, endoscopic ultrasound, positron emission tomography, and thoracoscopy/laparoscopy. The Annals of thoracic surgery 2002, 74(4):1026-1032.

21. Devesa SS, Blot WJ, Fraumeni JF Jr: Changing patterns in the incidence of esophageal and gastric carcinoma in the United States. Cancer 1998, 83(10):2049-2053.

22. DeMeester SR: Adenocarcinoma of the esophagus and cardia: a review of the disease and its treatment. Ann Surg Oncol 2006, 13(1):12-30.

23. Pohl $\mathrm{H}$, Welch HG: The role of overdiagnosis and reclassification in the marked increase of esophageal adenocarcinoma incidence. J Natl Cancer Inst 2005, 97(2):142-146.

24. Jemal A, Siegel R, Ward E, Hao Y, Xu J, Murray T, Thun MJ: Cancer statistics, 2008. CA Cancer J Clin 2008, 58(2):71-96.

25. Enzinger PC, Mayer RJ: Esophageal cancer. N Engl J Med 2003, 349(23):2241-2252.

26. Dolan K, Sutton R, Walker SJ, Morris Al, Campbell F, Williams EM: New classification of oesophageal and gastric carcinomas derived from changing patterns in epidemiology. Br J Cancer 1999, 80(5-6):834-842.

27. Bollschweiler E, Wolfgarten E, Gutschow C, Holscher AH: Demographic variations in the rising incidence of esophageal adenocarcinoma in white males. Cancer 2001, 92(3):549-555.

28. Chang DT, Chapman C, Shen J, Su Z, Koong AC: Treatment of esophageal cancer based on histology: a surveillance epidemiology and end results analysis. American journal of clinical oncology 2009, 32(4):405-410.

29. Fukuzawa K, Noguchi Y, Yoshikawa T, Saito A, Doi C, Makino T, Takanashi Y, Ito T, Tsuburaya A: High incidence of synchronous cancer of the oral cavity and the upper gastrointestinal tract. Cancer Lett 1999, 144(2):145-151.

30. Welz S, Schmid A, Hehr T, Schulze K, Feldmann HJ, Budach W, Bamberg M, Belka C: Treatment-outcome for synchronous head-and-neck and oesophageal squamous cell carcinoma. Radiotherapy and oncology: journal of the European Society for Therapeutic Radiology and Oncology 2005, 77(3):267-270.

31. Mariette C, Piessen G, Triboulet JP: Therapeutic strategies in oesophageal carcinoma: role of surgery and other modalities. Lancet Oncol 2007, 8(6):545-553.

32. Coia LR, Engstrom PF, Paul AR, Stafford PM, Hanks GE: Long-term results of infusional 5-FU, mitomycin- $\mathrm{C}$ and radiation as primary management of esophageal carcinoma. Int I Radiat Oncol Biol Phys 1991, 20(1):29-36.

33. Al-Sarraf M, Martz K, Herskovic A, Leichman L, Brindle JS, Vaitkevicius VK, Cooper J, Byhardt R, Davis L, Emami B: Progress report of combined chemoradiotherapy versus radiotherapy alone in patients with esophageal cancer. an intergroup study. J Clin Oncol 1997, 15(1):277-284.

34. Minsky BD, Pajak TF, Ginsberg RJ, Pisansky TM, Martenson J, Komaki R, Okawara G, Rosenthal SA, Kelsen DP: INT 0123 (Radiation Therapy Oncology Group 94-05) phase III trial of combined-modality therapy for esophageal cancer: high-dose versus standard-dose radiation therapy. Journal of clinical oncology: official journal of the American Society of Clinical Oncology 2002, 20(5):1167-1174.

35. Geh Jl, Bond SJ, Bentzen SM, Glynne-Jones R: Systematic overview of preoperative (neoadjuvant) chemoradiotherapy trials in oesophageal cancer: evidence of a radiation and chemotherapy dose response. Radiother Oncol 2006, 78(3):236-244.

36. Enestvedt CK, Perry KA, Kim C, McConnell PW, Diggs BS, Vernon A, O'Rourke RW, Luketich JD, Hunter JG, Jobe BA: Trends in the management of esophageal carcinoma based on provider volume: treatment practices of 618 esophageal surgeons. Diseases of the esophagus: official journal of the International Society for Diseases of the Esophagus/ISDE 2010, 23(2):136-144
37. Schwer AL, Ballonoff A, McCammon R, Rusthoven K, D'Agostino RB Jr, Schefter TE: Survival effect of neoadjuvant radiotherapy before esophagectomy for patients with esophageal cancer: a surveillance, epidemiology, and end-results study. International journal of radiation oncology, biology, physics 2009, 73(2):449-455.

38. Cronin-Fenton DP, Sharp L, Carsin AE, Comber H: Patterns of care and effects on mortality for cancers of the oesophagus and gastric cardia: a population-based study. European journal of cancer 2007, 43(3):565-575.

39. Brown LM, Hoover R, Silverman D, Baris D, Hayes R, Swanson GM, Schoenberg J, Greenberg R, Liff J, Schwartz A, et al: Excess incidence of squamous cell esophageal cancer among US Black men: role of social class and other risk factors. Am J Epidemiol 2001, 153(2):114-122.

40. Brenner B, Ilson DH, Minsky BD: Treatment of localized esophageal cancer. Seminars in oncology 2004, 31(4):554-565.

41. Koshy M, Esiashvilli N, Landry JC, Thomas CR Jr, Matthews RH: Multiple management modalities in esophageal cancer: combined modality management approaches. Oncologist 2004, 9(2):147-159.

42. Palma P, Conde-Muino R, Rodriguez-Fernandez A, Segura-Jimenez I, Sanchez-Sanchez R, Martin-Cano J, Gomez-Rio M, Ferron JA, LlamasElvira JM: The value of metabolic imaging to predict tumour response after chemoradiation in locally advanced rectal cancer. Radiat Oncol 2010, 5:119.

43. Kanakamedala MR, Packianathan S, Vijayakumar S: Lack of Cetuximab induced skin toxicity in a previously irradiated field: case report and review of the literature. Radiat Oncol 2010, 5:38

44. Du L, Zhou LJ, Pan XJ, Wang YX, Xu QZ, Yang ZH, Wang Y, Liu XD, Zhu MX, Zhou PK: Radiosensitization and growth inhibition of cancer cells mediated by an scFv antibody gene against DNA-PKcs in vitro and in vivo. Radiat Oncol 2010, 5:70.

45. Li M, Abdollahi A, Grone HJ, Lipson KE, Belka C, Huber PE: Late treatment with imatinib mesylate ameliorates radiation-induced lung fibrosis in a mouse model. Radiat Oncol 2009, 4:66.

46. Zerp SF, Stoter R, Kuipers G, Yang D, Lippman ME, van Blitterswijk WJ, Bartelink H, Rooswinkel R, Lafleur V, Verheij M: AT-101, a small molecule inhibitor of anti-apoptotic Bcl-2 family members, activates the SAPK/JNK pathway and enhances radiation-induced apoptosis. Radiat Oncol 2009, 4:47.

47. Scorsetti M, Navarria P, Mancosu P, Alongi F, Castiglioni S, Cavina R, Cozzi L, Fogliata A, Pentimalli S, Tozzi A, et al: Large volume unresectable locally advanced non-small cell lung cancer: acute toxicity and initial outcome results with rapid arc. Radiat Oncol 2010, 5:94.

48. Huang $T C$, Liang JA, Dilling $T$, Wu TH, Zhang G: Four-dimensional dosimetry validation and study in lung radiotherapy using deformable image registration and Monte Carlo techniques. Radiat Oncol 2010, 5:45.

49. Shi A, Zhu G, Wu H, Yu R, Li F, Xu B: Analysis of clinical and dosimetric factors associated with severe acute radiation pneumonitis in patients with locally advanced non-small cell lung cancer treated with concurrent chemotherapy and intensity-modulated radiotherapy. Radiat Oncol 2010, 5:35.

50. Yamashita H, Kobayashi-Shibata S, Terahara A, Okuma K, Haga A, Wakui R, Ohtomo K, Nakagawa K: Prescreening based on the presence of CT-scan abnormalities and biomarkers (KL-6 and SP-D) may reduce severe radiation pneumonitis after stereotactic radiotherapy. Radiat Oncol 2010, 5:32.

doi:10.1186/1748-717X-7-60

Cite this article as: Wolf et al:: Treatment strategies for oesophageal cancer - time-trends and long term outcome data from a large tertiary referral centre. Radiation Oncology 2012 7:60. 